Article

\title{
Effects of Rainfall Intensity and Slope Gradient on Runoff and Soil Moisture Content on Different Growing Stages of Spring Maize
}

\author{
Wenbin Mu ${ }^{1,2}$, Fuliang Yu ${ }^{1, *}$, Chuanzhe Li ${ }^{1,3}$, Yuebo Xie ${ }^{2}$, Jiyang Tian ${ }^{1}$, Jia Liu ${ }^{1,4}$, \\ and Nana Zhao ${ }^{5}$
}

1 State Key Laboratory of Simulation and Regulation of Water Cycle in River Basin, China Institute of Water Resources and Hydropower Research, No.1 Fuxing Road, Haidian District, Beijing 100038, China; E-Mails: muwenbin1883@126.com (W.M.); azhe051@163.com (C.L.); tjyshd@126.com (J.T.); jia.liu@iwhr.com (J.L.)

2 College of Hydrology and Water Resources, Hohai University, No.1 Xikang Road, Nanjing 210098, Jiangsu, China; E-Mail: xyb@hhu.edu.cn

3 State Key Laboratory of Water Resources and Hydropower Engineering Science, Wuhan University, No.8 Donghu South Road, Wuhan 430072, Hubei, China

4 State Key Laboratory of Hydrology-Water Resources and Hydraulic Engineering, Hohai University, Nanjing 210098, Jiangsu, China

5 Institute of Wetland Research, Chinese Academy of Forestry, No.1 Dongxiaofu Road, Beijing 100091, China; E-Mail: annazhao2009@163.com

* Author to whom correspondence should be addressed; E-Mail: yufl@iwhr.com; Tel.: +86-10-6878-5612.

Academic Editor: Miklas Scholz

Received: 27 April 2015 / Accepted: 5 June 2015 / Published: 17 June 2015

Abstract: The rainfall-runoff process (RRP) is an important part of hydrologic process.
There is an effective measure to study RRP through artificial rainfall simulation. This paper
describes a study on three growing stages (jointing stage, tasseling stage, and mature stage)
of spring maize in which simulated rainfall events were used to study the effects of various
factors (rainfall intensity and slope gradient) on the RRP. The RRP was tested with three
different rainfall intensities ( $0.67,1.00$, and $1.67 \mathrm{~mm} / \mathrm{min}$ ) and subjected to three different
slopes $\left(5^{\circ}, 15^{\circ}\right.$, and $\left.20^{\circ}\right)$ so as to study RRP characteristics in semiarid regions. Regression
analysis was used to study the results of this test. The following key results were obtained:
(1) With the increase in rainfall intensity and slope, the increasing relationship with rainfall 
duration, overland flow, and cumulative runoff, respectively, complied with logarithmic and quadratic functions before reaching stable runoff in each growing stage of spring maize; (2) The runoff coefficient increased with the increase in rainfall intensity and slope in each growing stages of spring maize. The relationship between runoff coefficient, slope, rainfall intensity, rainfall duration, antecedent soil moisture, and vegetation coverage was multivariate and nonlinear; (3) The runoff lag time decreased with the increase in rainfall intensity and slope within the same growing stage. In addition, the relationship between runoff lag time, slope, rainfall intensity, antecedent soil moisture, and vegetation coverage could also be expressed by a multivariate nonlinear equation; (4) The descent rate of soil infiltration rate curve increased with the increased rainfall intensity and slope in the same growing stage. Furthermore, by comparing the Kostiakov, Horton, and Philip models, it was found that the Horton infiltration model was the best for estimating soil infiltration rate and cumulative infiltration under the condition of test.

Keywords: RRP; rainfall intensity; slope angle; runoff amount; runoff coefficient; lag time; soil infiltration rate

\section{Instruction}

The rainfall-runoff process (RRP), as an important part of the hydrologic cycle, features temporal and spatial variation [1,2]. In a general way, saturation overland flow prevails in China's southern humid areas, while infiltration excess runoff prevails in northern semiarid areas [3]. As China's major grain-producing semiarid area, the northern part of China is now faced with two important issues. First, the water shortage severely restricts the local sustainable development of agriculture, economy, and society. Second, the rainstorms that sometimes occur in the semiarid area bring about flood. From this point of view, it is necessary to have a correct understanding of RRP's characteristics in semiarid regions so as to accurately select or build an effective hydrological model, and to provide strong support for China's food security [4].

RRP is closely related to many factors, such as rainfall intensity, terrain slope, land use, vegetation and soil properties, etc. Many researchers have carried out extensive research in these respects [4-7,11-14,17-19]. Analysis from the angle of rainfall intensity, the influence of rainfall intensity on runoff is not straightforward. On the one hand, increased rainfall intensity may lead to increased runoff, due to the fact that increased rainfall intensity may bring about the formation of the soil crust, and the development of such soil crusts would reduce the infiltration [8]. On the other hand, owing to the spatial heterogeneity in the infiltration characteristics of the soil surface, infiltration would increase with increased rainfall intensity and runoff might decrease $[9,10]$. There have been many studies performed on this aspect. Truman et al. have compared the effects of constant and variable rainfall intensity pattern on runoff in conventional and reduced tillage systems and showed that variable rainfall intensity events generally produced more runoff at the early stage of a rainfall-runoff event, whereas constant rainfall intensity produces more runoff in the later stages of the event [11]. Assouline and Ben-Hur described the effects of rainfall intensity and slope gradient on the dynamics of interrill erosion 
during soil surface sealing and proved that cumulative runoff at the end of a rainfall event was lower as slopes were steeper [12]. Huang et al. conducted rainfall tests to study the effects of rainfall intensity, underlying surface, and slope gradient on soil infiltration and pointed out that increases in rainfall intensity are not conducive to soil infiltration and may reduce the amount of infiltration [13]. Assouline and Ben-Hur also found that as the rainfall intensity increased, the infiltration curve decreased more quickly, and the steady infiltration rate was higher after a long exposure to rainfall [12]. Nassif et al. reported that there was a strong correlation between the steady-state infiltration and rain intensity for standard agricultural soil [14].

The influence of slope on RRP also has two sides. For one thing, with the increase in slope, the soil infiltration rate will decrease, which can increase the runoff amount [15-17]. For the other, the effective rainfall obtained by the soil bin will decrease as the slope increases. Many researchers have analyzed the effect of slope on RRP. Agassi et al. measured the effect of slope, aspect (windward vs. leeward), and phosphogypsum application on rain amount, runoff, and erosion in small field plots and found that the amount of runoff was not affected by slope on the windward aspect but decreased sharply on the leeward aspect as slope increased [18]. Nassif et al. studied the influence of slope on runoff and infiltration. The results showed that there appears to be some critical slope beyond which the peak runoff is relatively unaffected, while for permeable soils the greater the slope the lower the infiltration capacity and for impermeable soils little or no effect [14]. Cerdà and García-Fayos conducted a study about the influence of slope angle on sediment, water, and seed losses on badland landscapes and found that slope angle did not have any influence on the volume of runoff under the test conditions, while it had a clear influence on runoff initiation, with cracks and crusts as the main factors controlling the time to ponding and time to runoff [19]. Fox et al. carried out an experiment to study the influence of slope angle on final infiltration rate for interrill conditions and pointed out that changes in overland flow depth and surface storage are the main reason for the dominant influence of slope angle on infiltration rate [17].

The studies noted above were generally carried out on bare land, and rarely on covered land, e.g., spring maize. In addition, most RRP tests with artificial rainfall in China, especially the test-based analysis of RRP with different rainfall intensities and slopes, were performed on the Loess Plateau of China $[4,20,21]$, while few were on the semiarid regions. Therefore, this rainfall-runoff test was carried out under the condition of spring maize cover in the semiarid region. The soil type of this test was sandy loam, which was taken from the Test Base of IWHR (China Institute of Water Resources and Hydropower Research) in Daxing District, Beijing. Meanwhile, the soil has deposited more than two years in the soil bin and the soil properties were extremely similar to field soil. This paper aims to find out the effect of variation of rainfall intensity and slope on RRP throughout the growing stage of spring maize by the rainfall-runoff test.

The main objectives are as follows: (1) estimate effect of rainfall intensity and slope on RRP; (2) discuss the runoff coefficient with different rainfall intensities and slopes; (3) analyze the runoff lag time with different rainfall intensities and slopes; (4) discuss the effect of rainfall intensity and slope on soil infiltration rate. The findings of this study would supply a certain theoretical basis for the watershed hydrological processes of semiarid regions. 


\section{Materials and Methods}

\subsection{Experimental Materials}

The rainfall runoff simulation tests on spring maize in various growing stages were performed in the Key Laboratory of Soil Erosion and Dryland Agriculture on the Loess Plateau under the Institute of Soil and Water Conservation of the Chinese Academy of Sciences with a side-spray automatic rainfall simulation system. The spray nozzle of this system was $16 \mathrm{~m}$ in height and the terminal fall velocity of raindrop calculated by the equation was over $98 \%$ of that of natural raindrops [22]. The raindrops of this system distributed homogeneously and the largest raindrop diameter was $5 \mathrm{~mm}$; furthermore, the rainfall characteristics were similar to those of natural rainfall [23]. The soil bin was a mobile variable slope steel bin $\left(\mathrm{L} \times \mathrm{W} \times \mathrm{H}=200 \mathrm{~cm} \times 50 \mathrm{~cm} \times 60 \mathrm{~cm}\right.$; the slope was adjustable between 0 and $\left.30^{\circ}\right)$. Around the top part of the soil bin were $10 \mathrm{~cm}$-high iron sheets designed to prevent raindrop splash erosion and the lateral erosion-induced loss of surface water and soil. Moreover, the longitudinal section of the soil bin outlet was enclosed with an iron shutter for interflow observation, where a layer of gauze was arranged at the inner side to avoid lateral leakage and loss of soil during rainfall. The upper end and bottom of soil bin were furnished with a V-shaped flow guiding device (Figure 1) for checking the overland flow and interflow runoff processes. Furthermore, each RRP test was accompanied by a repeated test.

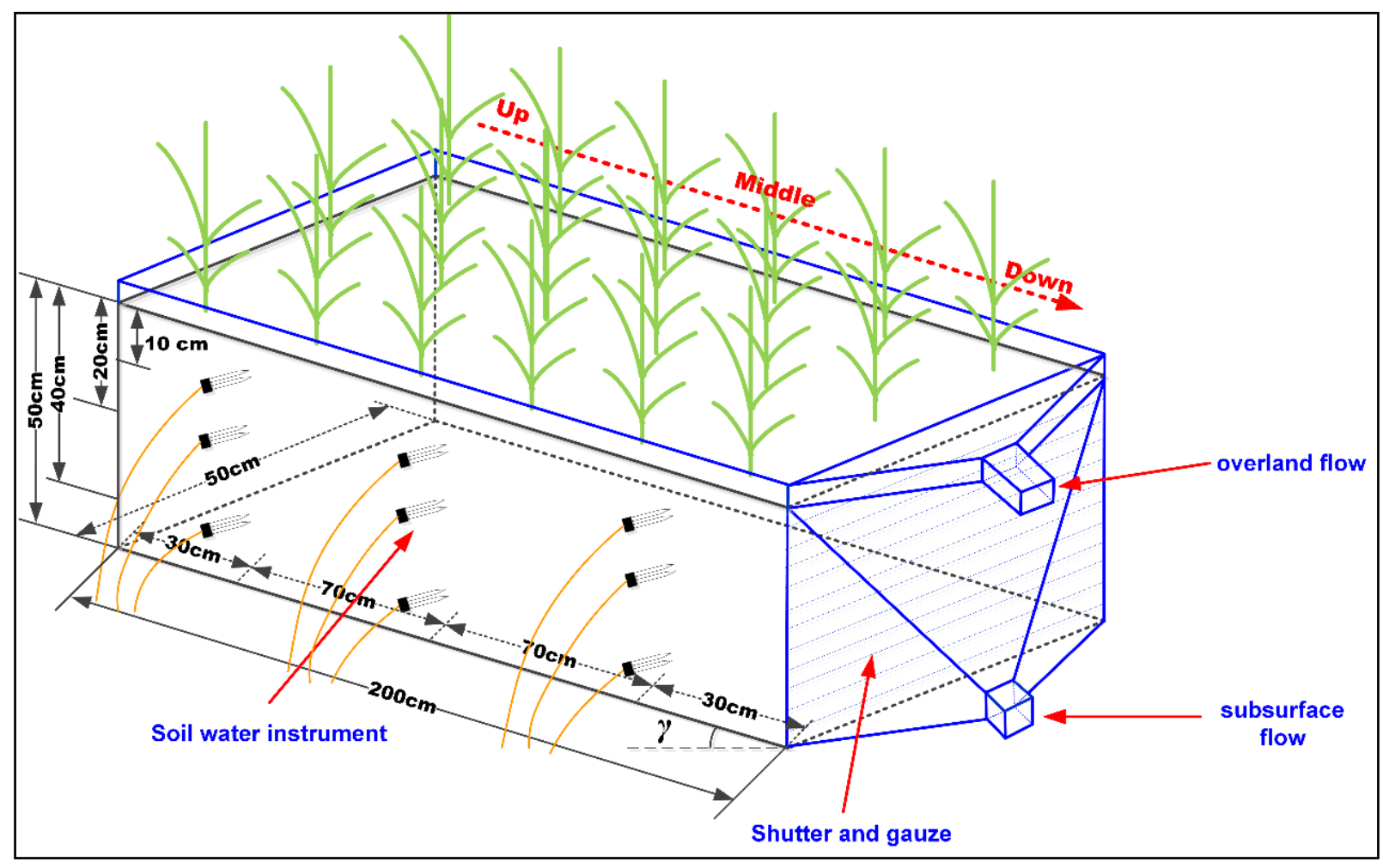

Figure 1. The structure of the experimental plots and soil water measurement instruments [4].

To monitor the dynamics of soil moisture during RRP, three groups of soil moisture sensors (EC-5) were mounted $30 \mathrm{~cm}, 100 \mathrm{~cm}$, and $170 \mathrm{~cm}$, respectively, away from the top. The depth of burying was $10 \mathrm{~cm}, 20 \mathrm{~cm}$, and $40 \mathrm{~cm}$ (Figure 1), respectively. The measurement error of EC-5 soil moisture sensor 
was $\pm 1 \%-2 \%$ (as given by the manufacturer), and its measurement accuracy was calibrated before installation. The data on soil moisture content were collected with data logger EM-50, of which the log time interval could be set between $1 \mathrm{~min}$ and $1440 \mathrm{~min}$.

\subsection{Measurements and Methods}

The sandy loam taken from the Test Base of China IWHR in Daxing District, Beijing was used for the test and put in the soil bin in March 2012. The test was launched in June 2014, when the soil properties of sandy loam were similar to the properties of field soil after a sedimentation process of over two years. Before the seeding of spring maize, cutting rings were used to randomly take soil samples from each soil bin, and the physical and chemical properties of the soil were analyzed as shown in Table 1. The row spacing and plant spacing of spring maize were $20 \mathrm{~cm}$ and $25 \mathrm{~cm}$, respectively. Rainfall runoff simulation test was performed in the jointing stage, tasseling stage, and mature stage of spring maize. The overland flow was measured manually. The time interval for overland flow measurement was 3 min during rainfall process, and when the rainfall stopped, the time interval changed to 1 min until the runoff stopped. If the interflow was observed throughout the RRP, the measure interval for interflow was $10 \mathrm{~min}$. In addition, the time interval set for the data logger was $1 \mathrm{~min}$ throughout the RRP. Since the groundwater level is extremely low in the northern part of China (for example, the mean groundwater level determined at Luancheng Test Station of the Chinese Academy of Sciences in Shijiazhuang in 2010 was about $37 \mathrm{~m}$ [24]), the interaction between ground water and soil moisture is negligible according to the scale of this test.

Table 1. Physical and chemical properties of sandy loam.

\begin{tabular}{|c|c|c|c|c|c|c|c|c|}
\hline $\begin{array}{c}\text { Soil } \\
\text { Bulk } \\
\text { Density }\end{array}$ & $\boldsymbol{\theta}_{s}$ & $\theta_{f}$ & $\boldsymbol{\theta}_{w}$ & $\boldsymbol{K}_{s}$ & $\begin{array}{c}\text { Total } \\
\text { Nitrogen }\end{array}$ & $\begin{array}{c}\text { Total } \\
\text { Phosphorus }\end{array}$ & $\begin{array}{c}\text { Total } \\
\text { Potassium }\end{array}$ & $\begin{array}{c}\text { Organic } \\
\text { Matter }\end{array}$ \\
\hline $\mathrm{g} / \mathrm{cm}^{3}$ & $\mathbf{m}^{3} / \mathbf{m}^{3}$ & $\mathbf{m}^{3} / \mathbf{m}^{3}$ & $\mathbf{m}^{3} / \mathbf{m}^{3}$ & $\mathrm{~mm} / \mathrm{min}$ & $\mathrm{g} / \mathrm{kg}$ & $\mathrm{g} / \mathrm{kg}$ & $\mathrm{g} / \mathrm{kg}$ & $\mathrm{g} / \mathrm{kg}$ \\
\hline 1.410 & 0.421 & 0.275 & 0.089 & 0.017 & 0.43 & 0.64 & 19.58 & 8.29 \\
\hline \multicolumn{9}{|c|}{$\begin{array}{l}\text { Notes: } \theta_{s}, \theta_{f}, \theta_{w} \text {, and } K_{s} \text { refer to saturated water content, field moisture capacity, wilting coefficient, and } \\
\text { saturated hydraulic conductivity, respectively; the assay method of total nitrogen, total phosphorus, total } \\
\text { potassium, and organic matter are Kjeldahl method, Mo-Sb colorimetric method, atomic absorption } \\
\text { spectroscopv, and gravimetric method, respectively. }\end{array}$} \\
\hline
\end{tabular}

Since the variety, planting time, management mode, and external environment of spring maize were consistent, the antecedent soil moisture content and vegetation coverage almost remain constant before the tests of each growing stage (Table 2). The design details are as follows:

(1) With different rainfall intensities, the slope of the soil bin was kept at $10^{\circ}$ throughout the whole growing stage. Three rainfall events with a duration of $62 \mathrm{~min}$ and a rainfall intensity of $0.67 \mathrm{~mm} / \mathrm{min}$, $1.00 \mathrm{~mm} / \mathrm{min}$, and $1.67 \mathrm{~mm} / \mathrm{min}$, respectively, were offered in each growing stage of spring maize.

(2) With different slopes, the rainfall intensity/duration was set to $0.5 \mathrm{~mm} / \mathrm{min} / 82 \mathrm{~min}$ for each soil bin. Furthermore, the three rainfall events were offered for each growing stage of spring maize with a constant slope of $5^{\circ}, 15^{\circ}$, and $20^{\circ}$ of the soil bin throughout the whole growing stage. 
Table 2. Antecedent soil moisture content and vegetation coverage for a rainfall-runoff test with different rainfall intensities in each growing stage.

\begin{tabular}{|c|c|c|c|}
\hline $\begin{array}{c}\text { Control } \\
\text { Condition } \\
\end{array}$ & Growing Stage & $\begin{array}{c}\text { Vegetation } \\
\text { Coverage (\%) }\end{array}$ & $\begin{array}{c}\text { Antecedent Soil Moisture } \\
\text { Content }\left(\mathrm{cm}^{3} / \mathrm{cm}^{3}\right) \\
\end{array}$ \\
\hline \multirow{3}{*}{$\begin{array}{l}\text { Rainfall } \\
\text { intensities }\end{array}$} & Jointing stage & 80 & $0.17 \pm 0.01$ \\
\hline & Tasseling stage & 93 & $0.13 \pm 0.01$ \\
\hline & Mature stage & 73 & $0.26 \pm 0.03$ \\
\hline \multirow{3}{*}{ Slope } & Jointing stage & 81 & $0.24 \pm 0.02$ \\
\hline & Tasseling stage & 95 & $0.13 \pm 0.03$ \\
\hline & Mature stage & 75 & $0.31 \pm 0.02$ \\
\hline
\end{tabular}

\subsection{Calculation Method}

Soil infiltration rate is an important indicator that describes the hillslope hydrological processes under rainfall conditions, and its change affects the formation of runoff. In order to analyze the dynamic variation of the soil infiltration rate in each growing stage of spring maize, the soil infiltration rate of this study could be obtained with Equation (1) based on the data of rainfall intensity, slope, and runoff, etc. [25]:

$$
f_{i}=(I \cdot t \cdot \cos \gamma-10 R / S) / t
$$

where $f_{i}$ means the mean infiltration rate of slope $(\mathrm{mm} / \mathrm{min}) ; I$ refers to rainfall intensity $(\mathrm{mm} / \mathrm{min})$; $\gamma$ represents the slope $\left(^{\circ}\right) ; t$ stands for the sampling interval (min); $R$ means the total runoff $(\mathrm{mL})$ within $t$; and $S$ is the rain-affected area of slope $\left(\mathrm{cm}^{2}\right)$.

\section{Results and Discussion}

\subsection{Analysis of RRP in Each Growing Stage of Spring Maize with Different Rainfall Intensities and Slopes}

In each growing stage of spring maize, the runoff process and cumulative runoff process with different rainfall intensities and slopes are shown in Figures 2 and 3, respectively. According to the results:

(1) The overland flow and cumulative runoff increased with the increase in rainfall intensity and slope, respectively.

(2) The relationship between overland flow and rainfall duration complied with a logarithmic function $(y=m \ln x+n)$ in each growing stage from the starting time of runoff to the time of stable runoff (Tables 3 and 4). The range of goodness-of-fit is $0.85-0.98$, and reached the significant level $(\eta=0.01)$ by $F$ test.

(3) Additionally, the relationship between cumulative runoff and rainfall duration complied with a quadratic function $\left(y=a x^{2}+b x+c\right)$ before reaching stable runoff(Table 3). The goodness-of-fit is 0.98 , and also reached the significant level $(\eta=0.01)$ by $\mathrm{F}$ test. The parameter $a$ was mainly affected by rainfall intensity and slope and the greater the rainfall intensity and slope was, the higher value $a$ would be. It was indicated that the growth rate of overland flow mainly depends on rainfall intensity and slope. 


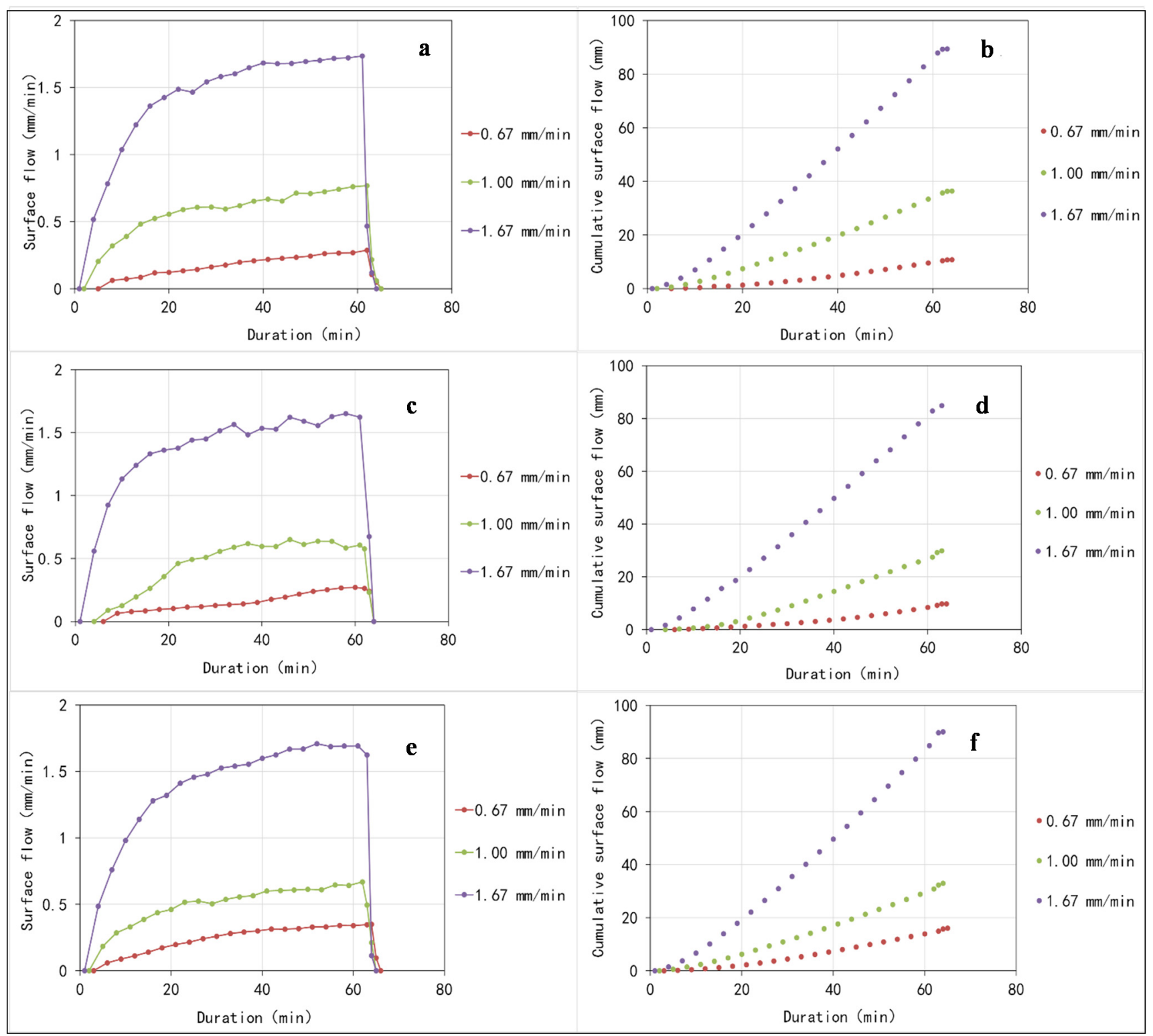

Figure 2. RRP and cumulative runoff in growing stage with different rainfall intensities (a), (c) and (e) show the RRP of jointing stage, tasseling stage, and mature stage, respectively, with different rainfall intensities; (b), (d) and (f) show the cumulative runoff process of these three stages, respectively, with different rainfall intensities.

\subsection{Analysis of Runoff Coefficient in Each Growing Stage of Spring Maize with Different Rainfall} Intensities and Slopes

\subsubsection{Analysis of Runoff Coefficient with Different Rainfall Intensities}

(1) Runoff coefficient $\alpha$ is a crucial parameter that describes the rainfall-runoff relationship. Within a single growing stage, the runoff coefficient increased with the increased rainfall intensity (Figure 4). The same conclusion has been come to by Wang et al., who studied the runoff characteristics of slope cropland in the hilly area of purple soil [26]. When $i=0.67 \mathrm{~mm} / \mathrm{min}$, the tasseling stage gave the smallest runoff coefficient while the mature stage offered the largest one in that the antecedent soil moisture content was the lowest in the tasseling stage and highest in the mature stage. When the rainfall intensity 
increased (i.e., $i=1.00 \mathrm{~mm} / \mathrm{min}$, or $i=1.67 \mathrm{~mm} / \mathrm{min}$ ), the runoff coefficient was nearly the same for each growing stage. In other words, the effect of such factors as coverage and antecedent soil moisture content on runoff coefficient decreased gradually with a high rainfall intensity, in which case the runoff coefficient was principally affected by rainfall intensity.
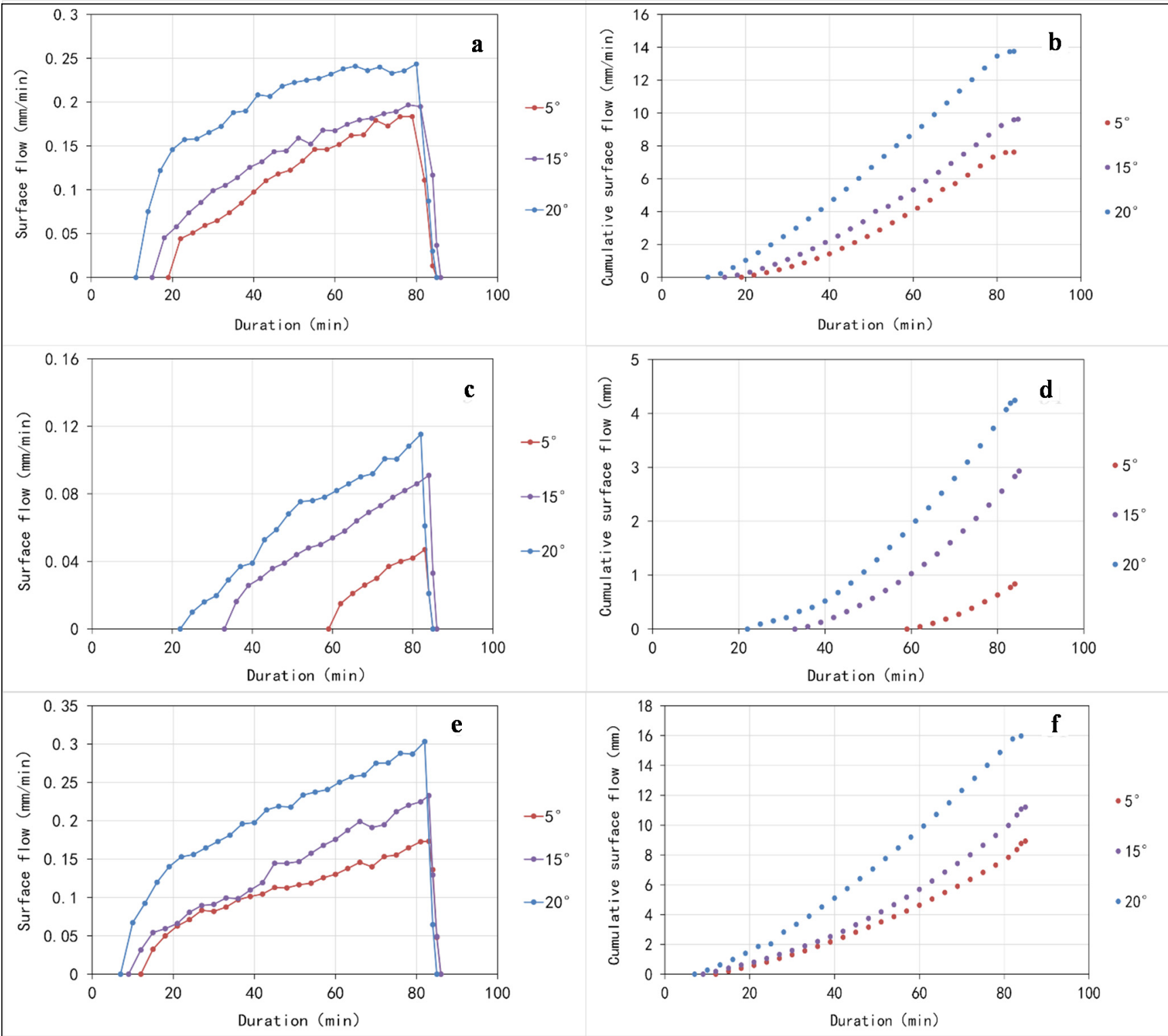

Figure 3. RRP and runoff accumulation process in growing stage with different slopes (a), (c) and (e) show the RRP of the jointing stage, tasseling stage, and mature stage, respectively, with different slopes; (b), (d) and (f) show the cumulative runoff process of these three stages, respectively, with different slopes).

(2) Among the nine rainfall events in each growing stage of spring maize with different rainfall intensities, the largest and smallest runoff coefficients were 0.85 and 0.28 , respectively. The major affecting factors for runoff coefficient $\alpha$ were rainfall intensity $i$, rainfall duration $t$, antecedent soil moisture content $\theta_{0}$, and vegetation coverage $v$. A study [27] reported that runoff coefficient exhibited a tendency of logarithmic increase with the increase in antecedent soil moisture content, and a tendency of power function-based decrease with the increase in coverage [28]. In consideration of the fact that the 
runoff coefficient increased with the increase in rainfall intensity and rainfall duration and gradually approached a certain value, this paper performed multivariate nonlinear regression analysis with particle swarm optimization by assuming that the relationship of runoff coefficient with rainfall intensity and rainfall duration was logarithmic. The expression is as follows:

$$
\alpha=0.569 \ln i+0.048 \ln t+0.004 \ln \theta_{0}+0.294 v^{-0.570},
$$

where $\alpha$ is the runoff coefficient $(\mathrm{mm} / \mathrm{mm}) ; i$ represents rainfall intensity $(\mathrm{mm} / \mathrm{min}) ; t$ stands for rainfall duration (min); $\theta_{0}$ means antecedent soil moisture content $\left(\mathrm{g} / \mathrm{cm}^{3}\right) ; v$ refers to vegetation coverage $\left(\mathrm{m}^{2} / \mathrm{m}^{2}\right)$; and the goodness of fit $R=0.97$.

Table 3. Regression analysis and goodness of fit of overland flow, cumulative runoff, and rainfall duration with different rainfall intensities.

\begin{tabular}{|c|c|c|c|c|c|c|c|c|c|}
\hline \multirow{2}{*}{$\begin{array}{c}\text { Growing } \\
\text { Stage }\end{array}$} & \multirow{2}{*}{$\begin{array}{c}\text { Rainfall Intensity } \\
(\mathbf{m m} / \mathbf{m i n})\end{array}$} & \multicolumn{3}{|c|}{$y=m \ln x+n$} & \multicolumn{4}{|c|}{$y=a x^{2}+b x+c$} & \multirow{2}{*}{$\begin{array}{c}\text { Variation Range } \\
\text { of } x(\mathrm{~min})\end{array}$} \\
\hline & & $m$ & $n$ & $R$ & $a$ & $b$ & $c$ & $R$ & \\
\hline \multirow{3}{*}{ Jointing stage } & 0.67 & 0.1173 & -0.2129 & 0.96 & 0.0022 & 0.0386 & -0.2791 & 0.98 & $x>5$ \\
\hline & 1.00 & 0.2162 & -0.1251 & 0.98 & 0.0030 & 0.4208 & -2.0373 & 0.98 & $x>2$ \\
\hline & 1.67 & 0.3711 & 0.2954 & 0.94 & 0.0059 & 1.1988 & -2.4536 & 0.98 & $x>1$ \\
\hline \multirow{3}{*}{ Tasseling stage } & 0.67 & 0.1197 & -0.2435 & 0.85 & 0.0017 & 0.0407 & -0.3830 & 0.98 & $x>6$ \\
\hline & 1.00 & 0.2600 & -0.3973 & 0.85 & 0.0037 & 0.2630 & -2.4034 & 0.98 & $x>4$ \\
\hline & 1.67 & 0.3872 & 0.1321 & 0.92 & 0.0051 & 1.0998 & -3.0373 & 0.98 & $x>1$ \\
\hline \multirow{3}{*}{ Mature Stage } & 0.67 & 0.1199 & -0.1574 & 0.96 & 0.0015 & 0.1610 & -1.4434 & 0.98 & $x>3$ \\
\hline & 1.00 & 0.1836 & -0.1011 & 0.98 & 0.0022 & 0.3949 & -2.1726 & 0.98 & $x>2$ \\
\hline & 1.67 & 0.4459 & -0.0337 & 0.98 & 0.0047 & 1.1614 & -4.5114 & 0.98 & $x>1$ \\
\hline
\end{tabular}

Table 4. Regression analysis and goodness of fit of overland flow, cumulative runoff, and rainfall duration with different slopes.

\begin{tabular}{|c|c|c|c|c|c|c|c|c|c|}
\hline \multirow{2}{*}{$\begin{array}{c}\text { Growing } \\
\text { Stage } \\
\end{array}$} & \multirow{2}{*}{ Slope $\left(^{\circ}\right)$} & \multicolumn{3}{|c|}{$y=m \ln x+n$} & \multicolumn{4}{|c|}{$y=a x^{2}+b x+c$} & \multirow{2}{*}{$\begin{array}{c}\text { Variation Range } \\
\text { of } x(\mathrm{~min})\end{array}$} \\
\hline & & $m$ & $n$ & $R$ & $a$ & $b$ & $c$ & $\boldsymbol{R}$ & \\
\hline \multirow{3}{*}{ Jointing stage } & 5 & 0.1068 & -0.2766 & 0.96 & 0.0010 & 0.0299 & -0.7738 & 0.98 & $x>19$ \\
\hline & 15 & 0.0920 & -0.1994 & 0.98 & 0.0009 & 0.0610 & 0.9236 & 0.98 & $x>15$ \\
\hline & 20 & 0.0834 & -0.1024 & 0.88 & 0.0006 & 0.1474 & -1.2652 & 0.98 & $x>11$ \\
\hline \multirow{3}{*}{ Tasseling stage } & 5 & 0.1108 & -0.442 & 0.96 & 0.0005 & -0.0324 & 0.0729 & 0.98 & $x>59$ \\
\hline & 15 & 0.0953 & -0.3309 & 0.98 & 0.0006 & -0.0158 & -0.2272 & 0.98 & $x>33$ \\
\hline & 20 & 0.0915 & -0.2909 & 0.98 & 0.0007 & -0.0096 & -0.2118 & 0.98 & $x>22$ \\
\hline \multirow{3}{*}{ Mature Stage } & 5 & 0.0500 & -0.1183 & 0.96 & 0.0004 & 0.0294 & -0.4474 & 0.98 & $x>12$ \\
\hline & 15 & 0.0754 & -0.1800 & 0.90 & 0.0008 & 0.0247 & -0.3179 & 0.98 & $x>9$ \\
\hline & 20 & 0.0792 & -0.1428 & 0.96 & 0.0009 & 0.0715 & -0.6603 & 0.98 & $x>7$ \\
\hline
\end{tabular}

\subsubsection{Analysis of Runoff Coefficient with Different Slopes}

(1) Within a single growing stage of spring maize, the runoff coefficient increased with the increase in slope (Figure 5). The same conclusion has been made in the literature [26]. The increased slope resulted in a decrease in the soil infiltration rate that led to the increase in runoff. Among the growing stages, the effect of rainfall intensity $(i=0.5 \mathrm{~mm} / \mathrm{min})$ on runoff coefficient was relatively small. Due to the high soil moisture content and low vegetation coverage in the mature stage, the runoff coefficient 
with various slopes was greater than in the other stages; the smallest runoff coefficients were observed with various slopes in the tasseling stage because of the low soil moisture content and high vegetation coverage.

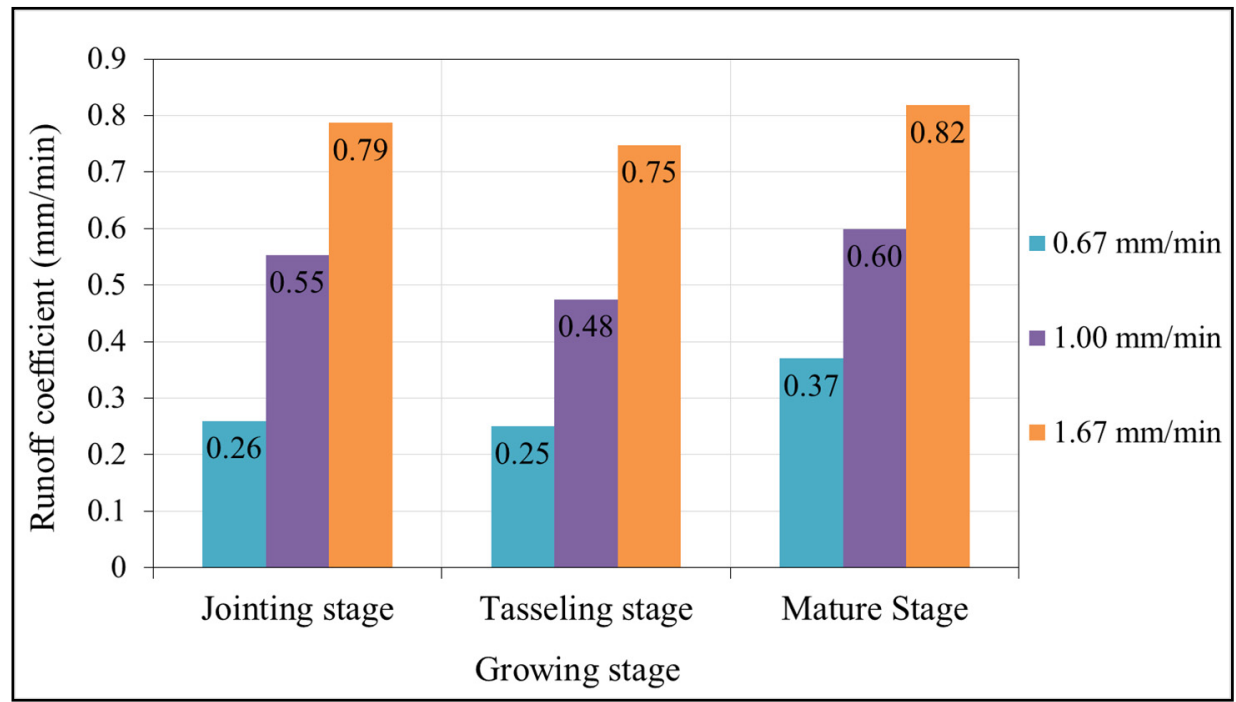

Figure 4. Variation of runoff coefficient in each growing stage with different rainfall intensities at a slope of 10 degrees.

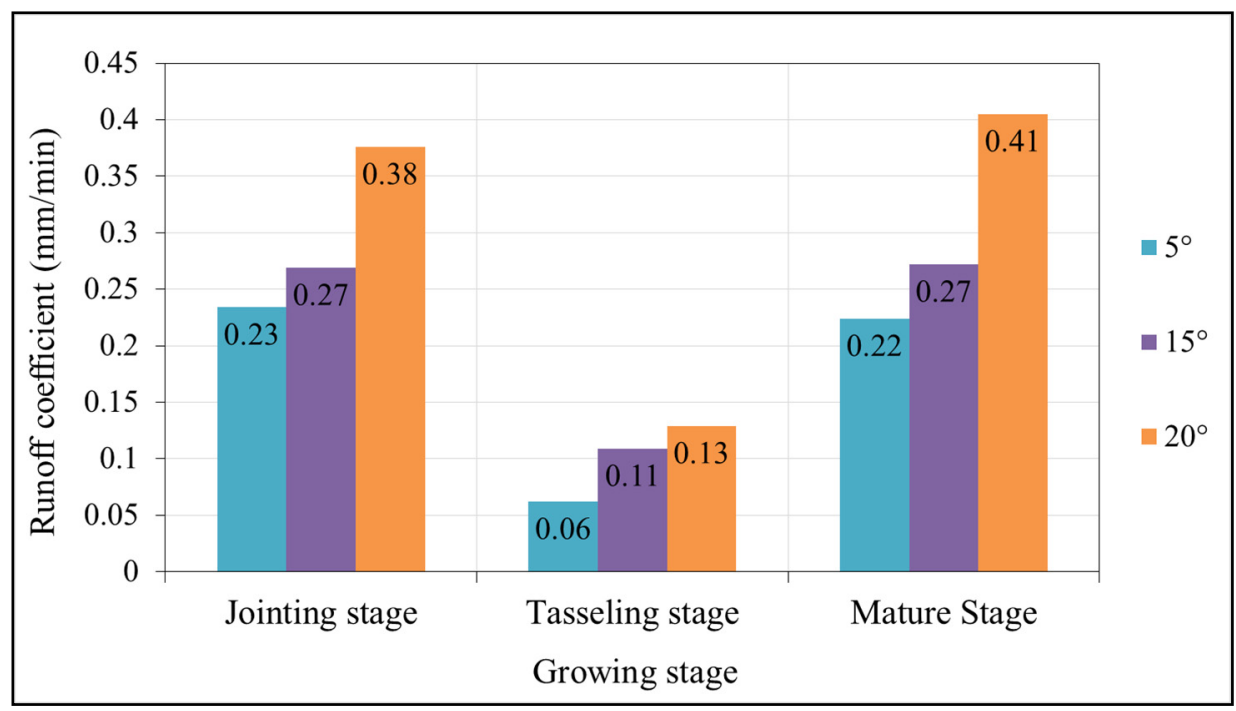

Figure 5. Variation of runoff coefficient in each growing stage with different slopes when the rainfall intensity is $0.5 \mathrm{~mm} / \mathrm{min}$.

(2) Among the nine rainfall events in each growing stage of spring maize with different slopes, the largest and smallest runoff coefficients were 0.34 and 0.07 , respectively. The major factors affecting the runoff coefficient $\alpha$ were slope $\gamma$, rainfall duration $t$, antecedent soil moisture content $\theta_{0}$, and vegetation coverage $v$. Relevant studies $[27,28]$ reported that the relationship of runoff coefficient with antecedent soil moisture content and vegetation coverage was logarithmic and power function-based, respectively. Seeing as the runoff coefficient increased with the increase in slope and rainfall duration and gradually approached a certain value, this paper performed multivariate nonlinear regression analysis with particle 
swarm optimization by assuming that the relationship of the runoff coefficient with the sine of slope and rainfall duration is logarithmic. The expression is as follows:

$$
\alpha=0.094 \ln (\sin \gamma)+0.149 \ln t+0.222 \ln \theta_{0}+0.012 v^{-0.586}
$$

where $\gamma$ means slope $\left(^{\circ}\right)$, and the other parameters are as shown in Equation (2); the goodness of fit $R=0.70$.

\subsubsection{Relationship between Runoff Coefficient and Various Affecting Factors}

According to the above-noted analysis, the relationship of runoff coefficient $\alpha$ with slope $\gamma$, rainfall intensity $i$, rainfall duration $t$, antecedent soil moisture content $\theta_{0}$, and vegetation coverage $v$ is expressed as:

$$
\alpha=0.066 \ln (\sin \gamma)+0.600 \ln i+0.150 \ln t+0.152 \ln \theta 0+0.250 v^{-0.180}
$$

where the parameters are the same as above; the goodness of fit $R=0.96$, and the sample number $n=18$.

\subsection{Analysis of Runoff Lag Time Variation in Each Growing Stage of Spring Maize with Different} Rainfall Intensities and Slopes

\subsubsection{Analysis of Runoff Lag Time with Different Rainfall Intensities}

Theoretically the runoff lag time is defined as the time from the center of mass of rainfall excess to the center of mass of direct runoff [30]. Since the rainfall is principally absorbed by vegetation interception, soil surface infiltration and the filling of soil macropores at the beginning of rainfall, there was an obvious time lag (i.e., the initial loss duration of rainfall) between the start of rainfall and the formation of overland flow. Runoff lag time reflects the slope runoff generation rate upon the occurrence of rainfall, and thus serves as an important indicator for describing the runoff generation rule [29]. Figure 6 showed the comparison among different growing stages of spring maize in respect of runoff lag time. According to the test results:

(1) Within a single growing stage, the runoff lag time decreased with the increase in rainfall intensity. Yuan et al. came to the same conclusion through a field rainfall runoff test [29], in that the effect of vegetation coverage and antecedent soil moisture content, etc. on runoff generation was lower under the condition of the greater rainfall intensity.

(2) Among the different growing stages, the rainfall intensity was so high $(i=1.67 \mathrm{~mm} / \mathrm{min})$ that the effect of vegetation coverage and antecedent soil moisture content on runoff lag time was negligible; therefore, the runoff lag time was almost the same. Under the condition of $i=1.0 \mathrm{~mm} / \mathrm{min}$, the longest runoff lag time was observed in the tasseling stage. The high vegetation coverage and low antecedent soil moisture content led to a considerable initial loss of runoff, thus resulting in the increase in runoff lag time. When $i=0.67 \mathrm{~mm} / \mathrm{min}$, the longest runoff lag time was still seen in the tasseling stage for the same reason with $i=1.0 \mathrm{~mm} / \mathrm{min}$. Furthermore, since the antecedent soil moisture content was higher in the mature stage than in the jointing stage and the coverage in the mature stage was lower than in the jointing stage, the runoff lag time of the mature stage was less than that of the jointing stage. 


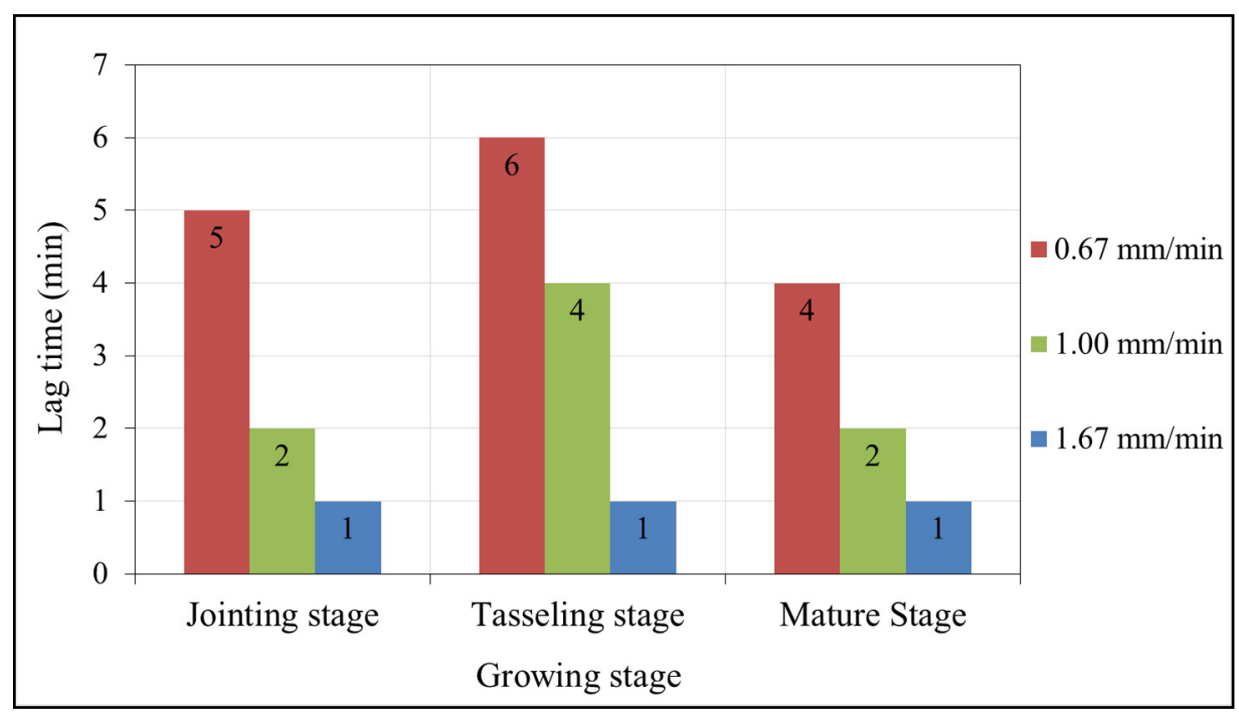

Figure 6. Variation of runoff lag time in each growing stage of spring maize with different rainfall intensities at a slope of $10^{\circ}$.

(3) Under the condition of different rainfall intensities, the lag time $t_{0}$ of surface runoff is immediately associated with rainfall intensity $i$, antecedent soil moisture content $\theta_{0}$, and vegetation coverage $v$ with different rainfall intensities. Considering that runoff lag time had a power function-based relation with rainfall intensity [28], a linear negative relation with antecedent soil moisture content [27], and a logarithmic relation with vegetation coverage [31], multivariate nonlinear regression analysis was performed with particle swarm optimization to determine the relationship between runoff lag time $t_{0}$ and various affecting factors based on RRP test data. The relational expression is as follows:

$$
t_{0}=3.81 i^{-1.17}+5.50 \ln v-0.0173 \theta_{0}
$$

where to means runoff lag time (min), and the other parameters are as shown in Equation (2); the goodness of fit $R=0.92$.

\subsubsection{Analysis of Runoff Lag Time with Different Slopes}

(1) Runoff lag time decreased with the increase in slope under the same external conditions within a single growing stage (Figure 7). The same conclusion has been derived from the literature [29]. This was mainly because the decrease in soil infiltration rate resulting from the increase in slope became a key factor in the point scale.

(2) The longest, the second longest, and the shortest runoff lag time were observed in the tasseling stage, jointing stage, and mature stage, respectively, at the same slope (Figure 7). One reason was that the high vegetation coverage and low soil moisture content in the tasseling stage resulted in a long runoff lag time. Another was that due to the lower vegetation coverage and higher antecedent soil moisture content in the mature stage than in the jointing stage, the shortest runoff lag time was observed in the mature stage. Hence, the vegetation coverage and antecedent soil moisture content were principal factors affecting rainfall runoff where rainfall intensity was relatively low. 


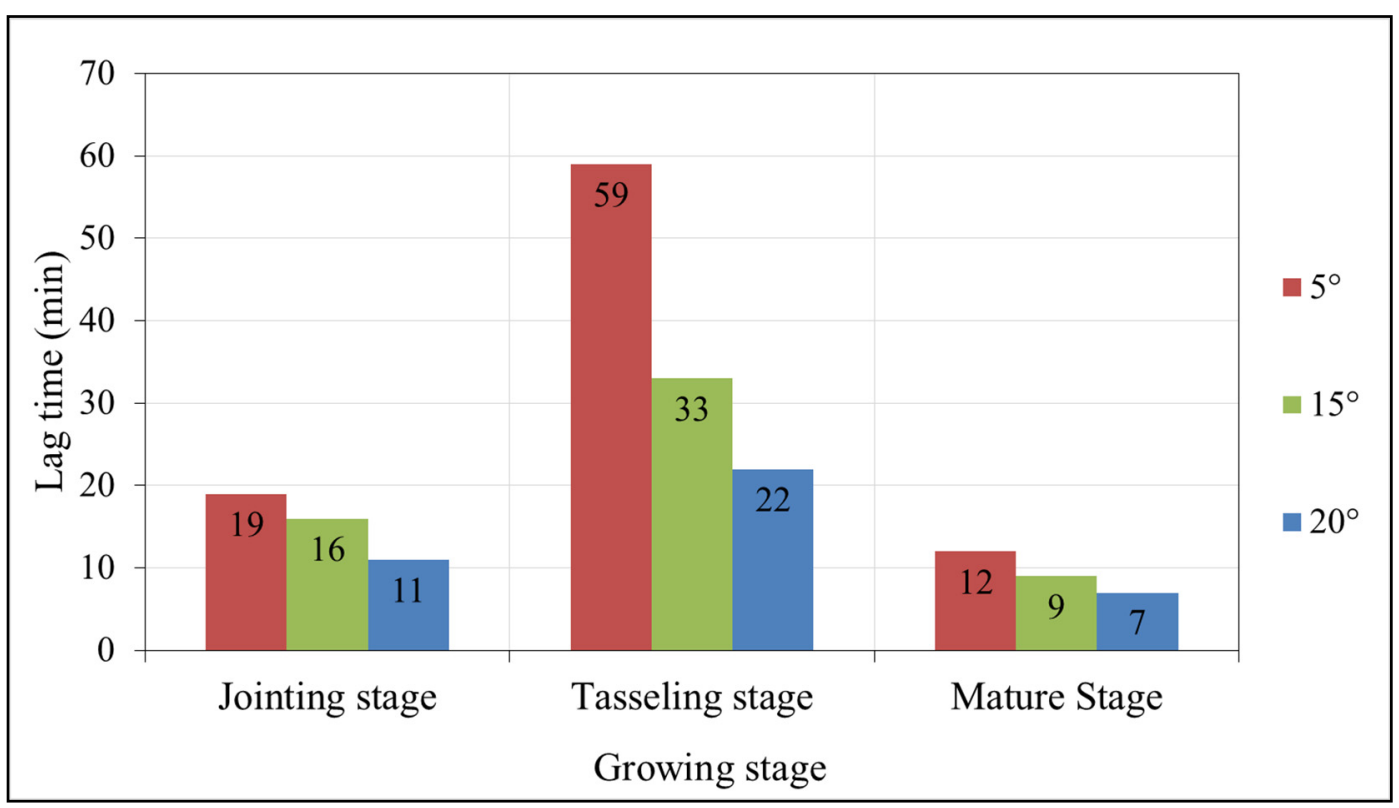

Figure 7. Variation of runoff lag time in each growing stage of spring maize with different slopes when the rainfall intensity is $0.5 \mathrm{~mm} / \mathrm{min}$.

(3) Under the condition of different slopes, the lag time to of overland flow was principally affected by the slope $\gamma$, antecedent soil moisture content $\theta_{0}$, and vegetation coverage $v$. Jiang and Huang researched into the rainfall runoff characteristics of old manured loessal soil with different slopes through the laboratory simulation of rainfall infiltration, and reported that the relationship between runoff lag time and the sine of slope was exponential [32]. In the meantime, runoff lag time exhibited a linear negative correlation with antecedent soil moisture content [27], and a logarithmic relationship with vegetation coverage [31]. Accordingly, multivariate nonlinear regression analysis was performed with particle swarm optimization based on RRP test data to determine the relationship between runoff lag time and various affecting factors. The relational expression is as follows:

$$
t_{0}=60.0 \exp (-1.43 \sin \gamma)-0.204 \theta_{0}+124 \ln v
$$

where the parameters are the same as in Equation (5); the goodness of fit $R=0.83$.

\subsubsection{Relationship between Runoff Lag Time and Various Affecting Factors}

According to the above-noted analysis, the relationship of runoff lag time $t_{0}$ with slope $\gamma$, rainfall intensity $i$, rainfall duration $t$, antecedent soil moisture content $\theta_{0}$, and vegetation coverage $v$ is expressed as:

$$
t_{0}=41.7 \exp (-2.51 \sin \gamma)+0.150 i^{-7.44}-118 \theta_{0}+1.80 \ln v
$$

where the parameters are the same as above; the goodness of fit $R=0.78$, and the sample number $n=18$. 


\subsection{Analysis of Dynamic Variation of Soil Infiltration Rate in Each Growing Stage of Spring Maize with Different Rainfall Intensities and Slopes}

The soil infiltration rate was calculated by Equation (1) based on the measured rainfall intensity and slope, etc. (Figure 8). As shown in Figure 8, the infiltration rate decreased gradually and eventually got relatively stable (i.e., stable infiltration rate) with the increase in rainfall duration. Figure $8 \mathrm{a}-\mathrm{c}$ showed that the soil infiltration rate curve became steep with the increase in rainfall intensity. Furthermore, the antecedent soil moisture content had a much lower effect on the soil infiltration rate as compared with the rainfall intensity in each growing stage, which indicated that the effect of antecedent soil moisture content on the soil infiltration rate decreased gradually with the increase in rainfall intensity [33]. Figure $8 \mathrm{~d}-\mathrm{f}$ showed that the soil infiltration rate might vary significantly depending on slope. The soil infiltration rate exhibited an obvious gentle downward trend when the slope was $5^{\circ}$, and showed the highest rate of descent at a slope of $20^{\circ}$. It was obvious that the increase in runoff resulting from the gradual decrease in soil infiltration rate was greater than the decrease in runoff arising from the decrease in receiving area as the slope increased. Furthermore, the soil infiltration rate in the tasseling stage was higher as compared with the other stages due to the relatively low antecedent soil moisture in the tasseling stage. This indicated that antecedent soil moisture could closely affect the soil infiltration rate under the premise of relatively low rainfall intensity; that is to say, the lower the antecedent soil moisture content was, the faster the descent rate of infiltration rate.

Traditional models of rainfall infiltration (i.e., the Kostiakov, Horton, and Philip models) were used to perform regression analysis on the rainfall-infiltration relationship with different rainfall intensities and slopes in each growing stage of spring maize (Tables 5 and 6). According to the results of Tables 5 and 6 :

(1) In view of the fact that the variation range of goodness-of-fit of the Kostiakov model was 0.85-0.99 and 0.89-0.99, respectively, and that the mean goodness-of-fit was 0.93 and 0.96 , respectively, this model exhibited a perfect fitting effect on the measured data. Parameter $b$ in the Kostiakov model reflected the decrease of infiltration rate with time, and its variation range is $0.40-1.54$ and $0.40-2.04$, respectively.

(2) In view of the fact that the variation range of goodness-of-fit of the Horton model was 0.96-0.99 and $0.91-0.99$, respectively, and that the mean goodness-of-fit was 0.98 and 0.97 , respectively, this model exhibited the best fitting effect on the measured data. The $k$ value in this model reflected the slope variation of infiltration curve, and the variation range was 8.82-85.81 and 11.24-359.51, respectively. The smaller the $k$ value was, the faster the infiltration rate decreased.

(3) The variation range of goodness-of-fit of the Philip model is $0.80-0.98$ and $0.84-0.99$, respectively, and the mean goodness-of-fit is 0.89 and 0.84 , respectively. The Philip model brought about poor results when compared with the Kostiakov and Horton models. This is largely attributable to the fact that the Philip equation is achieved under the assumption of semi-infinite homogeneous soil, homogeneously distributed initial soil moisture content, and water logging. Therefore, this equation is applicable only to one-dimensional vertical infiltration in homogeneous soil, and further research and perfection are still needed for heterogeneous soil. What is more, the natural infiltration happens under the condition of rainfall in most cases and greatly differs from ponding infiltration. Hence, the simulating effect of the Philip model was the lowest. 
The above analysis showed that the Horton infiltration model could satisfactorily estimate the soil infiltration rate and capacity, while the Kostiakov model exhibited favorable applicability. Zhao et al. and Liu et al. came to the same conclusion $[4,33]$.
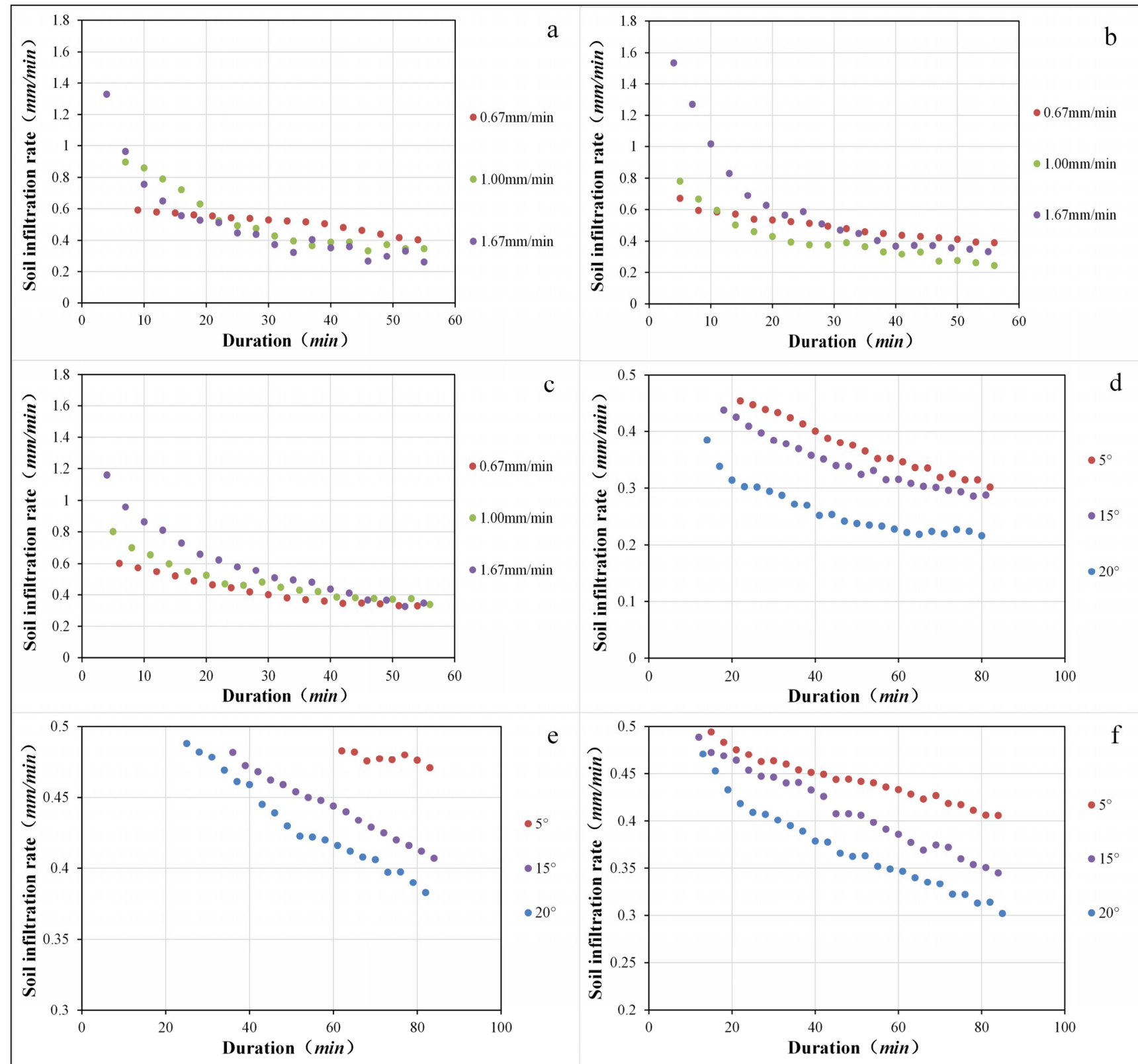

Figure 8. Curve of soil infiltration in growth period of spring maize: (a), (b) and (c) show the soil infiltration curves with different rainfall intensities in the jointing stage, tasseling stage, and mature stage, respectively; (d), (e) and (f) show the soil infiltration curves with different slopes in the three stages, respectively. 
Table 5. Regression analysis with rainfall infiltration models at different rainfall intensities.

\begin{tabular}{cccccccccccccc}
\hline \multirow{2}{*}{$\begin{array}{c}\text { Growth } \\
\text { Period }\end{array}$} & $\begin{array}{c}\text { Rainfall } \\
\text { Intensity }\end{array}$ & \multicolumn{3}{c}{ Kostiakov Model } & \multicolumn{3}{c}{ Horton Model } & \multicolumn{3}{c}{ Philip Model } \\
\cline { 3 - 14 } & $(\mathbf{m m} / \mathbf{m i n})$ & $\boldsymbol{a}$ & $\boldsymbol{b}$ & $\boldsymbol{R}$ & $\boldsymbol{a} \cdot \boldsymbol{t}^{-\boldsymbol{b}}$ & \multicolumn{3}{c}{$\boldsymbol{f}(\boldsymbol{t})=\boldsymbol{a}+\boldsymbol{b} \cdot \exp (-\boldsymbol{t} / \boldsymbol{k})$} & \multicolumn{3}{c}{$\boldsymbol{f}(\boldsymbol{t})=\boldsymbol{a} \cdot \boldsymbol{t}^{\mathbf{0 . 5}}+\boldsymbol{b}$} \\
\hline \multirow{3}{*}{ Jointing stage } & 0.67 & 1.030 & 0.236 & 0.95 & 0.285 & 0.398 & 43.364 & 0.99 & 1.064 & 0.257 & 0.89 \\
& 1.00 & 1.403 & 0.318 & 0.93 & 0.296 & 0.724 & 23.075 & 0.97 & 1.381 & 0.208 & 0.87 \\
& 1.67 & 1.938 & 0.378 & 0.85 & 0.320 & 1.540 & 12.698 & 0.99 & 1.851 & 0.181 & 0.80 \\
Tasseling & 0.67 & 1.058 & 0.229 & 0.88 & 0.147 & 0.522 & 85.811 & 0.96 & 1.104 & 0.020 & 0.82 \\
stage & 1.00 & 2.022 & 0.429 & 0.91 & 0.275 & 0.936 & 18.677 & 0.98 & 2.140 & 0.074 & 0.90 \\
& 1.67 & 1.818 & 0.416 & 0.92 & 0.324 & 1.506 & 8.816 & 0.99 & 1.773 & 0.108 & 0.90 \\
& 0.67 & 0.964 & 0.260 & 0.96 & 0.294 & 0.427 & 21.889 & 0.99 & 0.935 & 0.218 & 0.90 \\
Mature Stage & 1.00 & 1.475 & 0.355 & 0.99 & 0.324 & 0.712 & 15.771 & 0.97 & 1.522 & 0.154 & 0.98 \\
& 1.67 & 1.788 & 0.370 & 0.95 & 0.335 & 1.258 & 13.551 & 0.96 & 1.688 & 0.182 & 0.91 \\
\hline
\end{tabular}

Table 6. Regression analysis with rainfall infiltration models at different slopes.

\begin{tabular}{|c|c|c|c|c|c|c|c|c|c|c|c|}
\hline \multirow{3}{*}{$\begin{array}{l}\text { Growth } \\
\text { Period }\end{array}$} & \multirow{3}{*}{ Slope $\left(^{\circ}\right)$} & \multirow{2}{*}{\multicolumn{3}{|c|}{$\begin{array}{c}\text { Kostiakov Model } \\
f(t)=a \cdot t^{-b}\end{array}$}} & \multicolumn{4}{|c|}{ Horton Model } & \multirow{2}{*}{\multicolumn{3}{|c|}{$\begin{array}{c}\text { Philip Model } \\
f(t)=a \cdot t^{0.5}+b\end{array}$}} \\
\hline & & & & & & $t)=a+$ & $\cdot \exp (-t / k)$ & & & & \\
\hline & & $a$ & $b$ & $R$ & $a$ & $b$ & $\boldsymbol{k}$ & $R$ & $a$ & $b$ & $R$ \\
\hline \multirow{3}{*}{ Jointing stage } & 5 & 1.241 & 0.312 & 0.98 & 0.244 & 0.356 & 48.001 & 0.98 & 1.538 & 0.148 & 0.97 \\
\hline & 15 & 1.099 & 0.307 & 0.99 & 0.275 & 0.355 & 26.142 & 0.98 & 1.332 & 0.141 & 0.99 \\
\hline & 20 & 1.121 & 0.392 & 0.89 & 0.228 & 0.651 & 11.245 & 0.92 & 1.245 & 0.066 & 0.90 \\
\hline \multirow{3}{*}{ Tasseling stage } & 5 & 0.748 & 0.104 & 0.91 & 0.278 & 0.247 & 359.510 & 0.91 & 0.919 & 0.371 & 0.91 \\
\hline & 15 & 1.087 & 0.222 & 0.99 & 0.275 & 0.292 & 106.080 & 0.99 & 1.530 & 0.237 & 0.97 \\
\hline & 20 & 0.989 & 0.214 & 0.98 & 0.290 & 0.278 & 75.792 & 0.99 & 1.278 & 0.245 & 0.97 \\
\hline \multirow{3}{*}{ Mature Stage } & 5 & 0.658 & 0.105 & 0.97 & 0.341 & 0.175 & 88.036 & 0.98 & 0.540 & 0.658 & 0.93 \\
\hline & 15 & 0.762 & 0.168 & 0.91 & -0.046 & 0.559 & 89.008 & 0.99 & 0.760 & 0.286 & 0.84 \\
\hline & 20 & 0.822 & 0.218 & 0.98 & 0.267 & 0.264 & 47.323 & 0.98 & 0.940 & 0.220 & 0.96 \\
\hline
\end{tabular}

\section{Conclusion}

This paper probes into the dynamic variation of rainfall runoff and soil moisture content with different rainfall intensities and slopes in the jointing stage, tasseling stage, and mature stage of spring maize. Based on the test conditions and methods of this study, conclusions were drawn as follows:

(1) The overland flow and cumulative runoff increased with the increased rainfall intensity and slope in various growing stages of spring maize, respectively. The increasing relationship with rainfall duration, overland flow, and cumulative runoff, respectively, complied with logarithmic and quadratic functions before reaching stable runoff.

(2) The runoff coefficient $\alpha$ increased with the increase in rainfall intensity and slope. When the rainfall intensity was relatively low, the runoff coefficient was found to be the lowest in the tasseling stage and the highest in the mature stage, and was mainly affected by rainfall intensity along with the increase in rainfall intensity. At different slopes, the highest and lowest runoff coefficients were also observed in the mature stage and tasseling stage, respectively. Additionally, the relationship of $\alpha$ with slope $\gamma$, rainfall intensity $i$, rainfall duration $t$, antecedent soil moisture $\theta_{0}$, and vegetation coverage $v$ could be expressed by the equation $\alpha=0.066 \ln (\sin \gamma)+0.600 \ln i+0.150 \ln t+0.152 \ln \theta_{0}+0.250 v^{-0.180}$. 
(3) Within the same growing stage, runoff lag time to decreased with the increase in rainfall intensity and slope. Due to the influence of vegetation coverage and antecedent soil moisture, the tasseling stage offered the longest runoff lag time among the whole growing stages of spring maize with different rainfall intensities and slopes. In addition, $t_{0}$ was principally affected by $\gamma, i, \theta_{0}$, and $v$, and the relationship could be expressed by the equation $t_{0}=41.7 \exp (-2.51 \sin \gamma)+0.150 i^{-7.44}-118 \theta_{0}+1.80 \ln v$.

(4) The descent rate of the soil infiltration rate curve was directly proportional to the increased rainfall intensity in various growing stages of spring maize and the effect of antecedent soil moisture content on the soil infiltration rate decreased gradually. When the rainfall intensity was relatively low, the antecedent soil moisture could significantly affect soil infiltration rate at different slopes. With the increase in slope, the increasing value in runoff resulting from the gradual decrease in soil infiltration rate was greater than the decreasing value in runoff arising from the decrease in receiving area. Furthermore, with respect to the sandy loam in this test, the Horton infiltration model could satisfactorily estimate the soil infiltration rate and capacity, while the Kostiakov model exhibited favorable applicability.

In view of the constraints of the test conditions, this paper mainly studied the influences of different rainfall intensity and slope on the RRP and soil moisture content throughout the growing stage of spring maize. It is hoped that this study may gain more insight into the interactions among slope gradient, rainfall intensity, runoff, and soil infiltration and be of great significance in understanding the water cycle mechanism in semiarid regions. Furthermore, this paper only analyzes the relationship among rainfall intensity, slope, runoff, and soil infiltration rate. Meanwhile, the scale of the soil bin is too small based on the constrained test conditions. Therefore, it is necessary to expand the study scale and apply the test study to the influence of other factors on the RRP, e.g., vegetation, soil properties, soil crust, etc.

\section{Acknowledgments}

This study was supported by the Foundation of China Institute of Water Resources and Hydropower Research (1232), the International Science and Technology Cooperation Program of China (Grant No. 2013DFG70990), the National Natural Science Foundation of China (Grant Nos. 51209225 and 51409270), the Open Research Fund Program of State Key Laboratory of Water Resources and Hydropower Engineering Science (2012B093), and the Open Research Fund Program of State Key Laboratory of Hydrology-Water Resources and Hydraulic Engineering (2014490611).

\section{Author Contributions}

The experimental studies were designed by all five co-authors under the supervision of Fuliang $\mathrm{Yu}$ and Yuebo Xie. Specifically, Wenbin Mu, Chuanzhe Li, and Jiyang Tian performed the experiments and analyzed the data. Jia Liu designed the framework and Nana Zhao checked for mistakes in the English writing. 


\section{Conflicts of Interest}

The authors declare no conflict of interest.

\section{References}

1. Van de Giesen, N.C.; Stomph, T.J.; de Ridder, N. Scale effects of Hortonian overland flow and rainfallrunoff dynamics in a West African catena landscape. Hydrol. Process. 2000, 14, 165-175.

2. Bryan, R.B.; Poesen, J. Laboratory experiments on the influence of slope length on runoff, percolation and rill development. Earth Surf. Proc. Land. 1989, 14, 211-231.

3. East China Institute of Water Conservancy. Methods for Forecasting Floods in Humid Areas of China; Water Resources and Electric Power Press: Beijing, China, 1978.

4. Zhao, N.; Yu, F.; Li, C.; Wang, H.; Liu, J.; Mu, W. Investigation of rainfall-runoff processes and soil moisture dynamics in grassland plots under simulated rainfall conditions. Water 2014, 6, 2671-2689.

5. Stomph, T.J.; de Ridder, N.; Steenhuis, T.S.; van de Giesen, N.C. Scale effects of Hortonian overland flow and rainfall-runoff dynamics: Laboratory validation of a process-based model. Earth Surf. Proc. Land. 2002, 27, 847-855.

6. Gómez, J.A.; Nearing, M.A. Runoff and sediment losses from rough and smooth soil surfaces in a laboratory experiment. Catena 2005, 59, 253-266.

7. Truman, C.C; Potter, T.L.; Nuti, R.C.; Franklin, D.H.; Bosch, D.D. Antecedent water content effects on runoff and sediment yields from two Coastal Plain Ultisols. Agric. Water Manag. 2011, 98, 1189-1196.

8. Hawkins, R.H. Interpretations of Source Area Variability in Rainfall-Runoff Relations. In International Symposium on Rainfall-Runoff Modeling; Water Resources Publications: Littleton, CO, USA, 1981; pp. 303-324.

9. Römkens, M.J.M.; Prasad, S.N.; Parlange, J.Y. Surface seal development in relation to rainstorm intensity. Catena Suppl. 1990, 17, 1-11.

10. Parsons, A.J.; Stone, P.M. Effects of intra-storm variations in rainfall intensity on interrill runoff and erosion. Catena 2006, 67, 68-78.

11. Truman, C.C.; Strickland, T.C.; Potter, T.L.; Franklin, D.H.; Bosch, D.D.; Bednarz, C.W. Variable rainfall intensity and tillage effects on runoff, sediment, and carbon losses from a loamy sand under simulated rainfall. J. Environ. Qual. 2007, 36, 1495-1502.

12. Assouline, S.; Ben-Hur, M. Effects of rainfall intensity and slope gradient on the dynamics of interrill erosion during soil surface sealing. Catena 2006, 66, 211-220.

13. Huang, J.; Wu, P.; Zhao, X. Effects of rainfall intensity, underlying surface and slope gradient on soil infiltration under simulated rainfall experiments. Catena 2013, 104, 93-102.

14. Nassif, S.H.; Wilson, E.M. The influence of slope and rain intensity on runoff and infiltration. Hydrol. Sci. J. 1975, 20, 539-553.

15. Sharma, K.; Singh, H.; Pareek, O. Rainwater infiltration into a bare loamy sand. Hydrol. Sci. J. 1983, 28, 417-424. 
16. Luk, S.H.; Cai, Q.; Wang, G.P. Effects of surface crusting and slope gradient on soil and water losses in the illy loess egion, North China. Catena Suppl. 1993, 24, 29-45.

17. Fox, D.M.; Bryan, R.B.; Price, A.G. The influence of slope angle on final infiltration rate for interrill conditions. Geoderma 1997, 80, 181-194.

18. Agassi, M.; Morin, J.; Shainberg, I. Slope, aspect, and phosphogypsum effects on runoff and erosion. Soil Sci. Am. J. 1990, 54, 1102-1106.

19. Cerdà, A.; García-Fayos, P. The influence of slope angle on sediment, water and seed losses on badland landscapes. Geomorphology 1997, 18, 77-90.

20. Yang, J.; Zhao, T.; Sun, B.; Sun, L. Kinematic Wave Theory and It's Application in Slope Runoff Simulation. J. Beijing For. Univ. 1992, 15, 1-11.

21. Zhang, G.H.; Jiang, D.S.; Shao, M.G. Runoff processes simulation on land based on unsaturated soil physical properties. J. Mt. Sci. Engl. 2001, 19, 14-18.

22. Xu, R. On the kinetic energy calculation method for natural and artificial rainfalls. Bull. Soil Water Conserv. 1983, 3, 37-39.

23. Zhou, P.H.; Zhang, X.D.; Tang, K.L. The rainfall simulator in soil erosion simulation test hall of the State Key Laboratory of Soil Erosion and Dryland Agriculture on the Loess Plateau. Bull. Soil Water Conserv. 2000, 20, 28-30.

24. Zhang, Y.; Wang, J.; Jing, J.; Sun, J. Response of Groundwater to Climate Change under Extreme Climate Conditions in North China Plain. J. Earth Sci. 2014, 25, 612-618.

25. Pan, C.Z.; Shangguan, Z.P. Runoff hydraulic characteristics and sediment generation in sloped grassplots under simulated rainfall conditions. J. Hydrol. 2006, 331, 178-185.

26. Wang, T.; Zhu, B.; Luo, Z.X.; Zhang, J. Runoff characteristic of slope cropland in the hilly area of purple soil. J. Soil Water Conserv. 2008, 22, 30-34.

27. Zhang, X.Y.; Shi, X.; Yu, D. Effect of antecedent soil moisture on the runoff and sediment characteristics of red soil slope. Adv. Water Sci. 2010, 21, 23-29.

28. Li, M.; Yao, W.; Ding, W.; Yang, J.; Chen, J. Effect of grass coverage on sediment yield in the hillslope-gully side erosion system. J. Geogr. Sci. 2009, 19, 321-330.

29. Yu, J.; Yang, C.; Liu, C.; Song, X.; Hu, S.; Li, F.; Tang, C. Slope runoff study in situ using rainfall simulator in mountainous area of North China. J. Geogr. Sci. 2009, 19, 461-470.

30. Grimaldi, S.; Petroselli, A.; Tauro, F.; Porfiri, M. Time of concentration: A paradox in modern hydrology. Hydrolog. Sci. J. 2012, 57, 217-228.

31. Yuan, J.P.; Jiang, D.S.; Gan, S. Analysis of factors affecting the rainfall runoff duration of slope. J. Mt. Sci. 1999, 17, 259-264.

32. Jiang, D.S.; Huang, G.J. Simulation test on the effect of ground slope on rainfall infiltration. Bull. Soil Water Conserv. 1984, 4, 10-13.

33. Liu, H.; Lei, T.W.; Zhao, J.; Yuan, C.P.; Fan, Y.T.; Qu, L.Q. Effects of rainfall intensity and antecedent soil water content on soil infiltrability under rainfall conditions using the run off-on-out method. J. Hydrol. 2011, 396, 24-32.

(C) 2015 by the authors; licensee MDPI, Basel, Switzerland. This article is an open access article distributed under the terms and conditions of the Creative Commons Attribution license (http://creativecommons.org/licenses/by/4.0/). 